\title{
Learning Stupidity
}

\section{James F Welles*}

P 0 Box 17, East Marion, New York, USA

\section{Introduction}

ISSN: 2637-8078

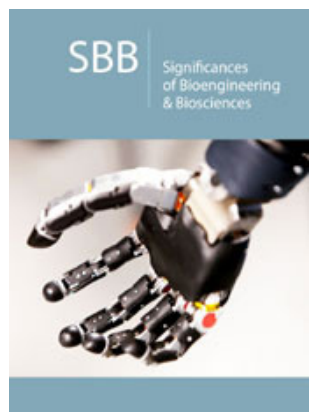

*Corresponding author: James F Welles, P 0 Box 17, East Marion, New York, USA

Submission: 漹 January 03, 2020

Published: 眥January 23, 2020

Volume 4 - Issue 1

How to cite this article: James F Welles. Learning Stupidity. Significances Bioeng Biosci.4(1). SBB.000576.2020.

DOI: 10.31031/SBB.2020.04.000576

Copyright@ James F Welles, This article is distributed under the terms of the Creative Commons Attribution 4.0 International License, which permits unrestricted use and redistribution provided that the original author and source are credited.
Arbitrary judgments would be easier to make and there would be much more concurrence in them were we not so amazing in our ability to learn. This is one of those general animal capacities which humans have taken to a dubious extreme. We can learn almost anything. The problem is that we are not limited by reality to learning just what exists or occurs. Our schemas may not only keep us from learning what is but help us, by illogical extensions, learn things that are not e.g., anyone else's religion.

The creative mind which invents new possible relationships among objects or combinations of them may be committing an act of genius or stupidity, depending on whether reality can be brought into congruence with the new ideas. However, that mind will be labeled "Genius" or "Stupid" according to its conformity to the demands and desires of the reference group. The act of reorganizing cognitions is of no value, except that it expands and enhances our potential for understanding and perhaps controlling the environment. Just how efficiently we do this and whether for good or evil depends on our cognitive abilities and the morality of our standards for judging. One very real drawback to this process of learning by evaluating new creations is that there are so many errors made along the way. Not only may new ideas or inventions be faulty, but the standards for evaluating them may be not only inherently biased toward the status quo but faulty (or inappropriate): ergo, the long human tradition of disasters born in the conditions of complacence, absurdity, vice and folly.

The emotional context of learning is difficult to overestimate because the cognitions accompanying various temperamental states are so fleeting-and thus difficult to pound into one's memory. Eternal values like truth, honor and integrity require long periods of incubation and are likely to fade without continual reinforcement [1]. In the context of learning, stupidity may be the price paid for the benefits of imagination. The value gained by an occasional good idea by a mind wandering beyond immediacy more than compensates for the many useless, silly or even dangerous notions so common in our mental life. Imagination may thus be viewed as increasing the range of stupidity while providing options for cultural advancement. As mentioned earlier, some maladaptive behavior is simply inefficiency-noise in the system. However, maladaptive behavior may also be indicative of cognitions straying from the narrow confines of the conventional schema. While the initial reaction to any such deviation from the norm may be negative, every so often one such variation will catch on and be appreciated as a positive mutation in the cultural life of a reference group.

This method of adjustment permits social evolution in gradual steps when novel contributions are minor and perhaps limited to circumstances. The major leaps of genius are often cognitively as well as emotionally incomprehensible to the majority in a group. However, they can serve either as beacons for guiding future development (if they are constructive) or as sirens for luring the unwary into fruitless pursuits (if they are just alluring). Naturally, neither adopting novel modes of thought and behavior nor adhering to convention is stupid. That evaluation is circumstantial, arbitrary and subjective. That process of evaluation, however, is most biased toward conforming to the status quo. Language, tradition and norms all support the familiar and tend to make anything new suspect. 
Traditions and norms further tend to stunt cultural development by way of the neurotic paradox, since the immediate, short-term rewards of conforming to expectation are usually most real and compelling . Language prejudices judgment by the nature of emotional values associated with certain terms. Accordingly, accepted behavior may be reinforced despite real, long-term detrimental consequences. The condition of a consistent, contented culture or, alternatively, one with balanced development might be ideal but not typically human. This is because the schema automatically favors itself, perverts the process of cultural evaluation into one of self-confirmation and tends to steer evolution toward conformity. This is not to say progress is impossible or just illusionary, nor that we simply must select among various forms of stupidity. There is change, and it can be for the better, if one can set a standard for judgment. The problem is that we do not set a standard for judgment; we set any number of standards which are very much conditioned if not determined by who we are. Perhaps the miracle is not that we have so much conflict and confusion in the world but that we have so little.

\section{References}

1. Bonhoeffer D Quoted on pages 542-543 by Gilbert. 